\title{
Effect of Vibration on Resistance Force of Plough
}

\author{
Vasilenko V. V. \\ Voronezh Agrarian University, \\ 394087, Voronezh, Michurin Av., 1, Russia \\ E-mail: vladva.vasilenko@yandex.ru
}

\author{
Vasilenko S. V. \\ Voronezh Agrarian University, \\ 394087, Voronezh, Michurin Av., 1, Russia \\ Voronezh, Russia
}

\author{
Achkasova N N \\ Financial University under the Government \\ of the Russian Federation \\ Moscow, Leningradsky prospect, 49, Russia
}

\begin{abstract}
Vibration of the working bodies decreases the force of traction resistance of the plough for ploughing the soil. Vibration is spontaneous and forced. Spontaneous vibration comes from the variable resistance of the soil, and forced vibration requires additional energy and transmission mechanisms. Vibration reduces friction force. Laboratory experiments revealed a decrease in the angle of friction of the soil against steel from 31.4 to $26.5^{\circ}$ at an amplitude of 2 to $4 \mathrm{~mm}$ and a frequency of 22 to 24 Hz. Theoretical calculations show that only due to vibration, it is possible to reduce the traction resistance of the working body of the plow by $9.7 \%$ at a speed of $2.0 \mathrm{~m} / \mathrm{s}$. In addition, the vibration contributes to the formation of advanced cracks in the soil, eliminates soil sticking and accumulation of weed vegetation on the working bodies. Spontaneous vibration has a low speed, so its direction should not coincide with the direction of movement of the plow, but occurs in the transverse or in the vertical direction. On two experimental plows, the working bodies were attached to the frame by means of strip racks made of spring steel. The strips were assembled into packages of four and are oriented along the direction of motion to obtain the lateral oscillations. During operation of the plow, the amplitude of the working body oscillations reached $5 \mathrm{~mm}$, and the frequency was 8-10 $\mathrm{Hz}$. The traction resistance of the plough has decreased by $14.5 \%$. Another plough in the conditions of long-term operation provided an increase in the productivity of the unit by $18 \%$. The most simple design solution for forced vibration of the plough can be implemented by replacing the support wheel with a metal correct polyhedron, which will provide vertical vibrations of the entire plough. The frequency and amplitude of the oscillations depend on the speed of movement, the number of faces and the overall size of the polyhedron.
\end{abstract}

Keywords—plough, soil treatment, resistance force, vibration.

\section{INTRODUCTION}

In any soil treatment, the vibrating working body creates less traction resistance than the same shape and size of the working body, but it is passive. The pilot study given in publication [1] proves that the power of resistance of the working bodies of plough or bulldozer type is lowered to the level of $71-93 \%$, if you apply the vibration. This effect is manifested in different types of soil and different humidity. The authors believe that the reduction of the traction force is due to the violation of cohesion and increase of tension between soil conglomerates. At the same time, the mechanical power that excites the vibration of the working body in the longitudinal direction depends on the frequency. In the destruction of the layer, which is below the depth of plowing, or the so-called plow sole, a decrease in thrust in the case of vibration was also noticed. The vibration was transmitted to the working body by means of a crank mechanism. The reduction in thrust was $14 \%$, but fuel consumption increased by $22 \%$ [2]. When loosening the soil in the vineyards of Australia, a decrease in the resistance force of the working body by $26.3 \%$ was recorded with an increase in power costs by $68.7 \%$ [3]. The optimal frequency of reduction of power consumption was determined under 4.86 $\mathrm{Hz}$. According to [4], the strength of the resistance of the vibrating body is $0.63-0.93$ of the strength of the resistance of the body without vibration, but the total energy consumption for the movement of the working body and its vibration increased by $41-45 \%$. The benefits of vibration during the digging of peanuts are reported in the source [5]. The tractor moved with a speed of 2.4 and $4.8 \mathrm{~km} / \mathrm{h}$ and vibration with a frequency of 9.0 and $16.7 \mathrm{~Hz}$ and an amplitude of 3.2 and 9.6 $\mathrm{mm}$ was applied. The energy for the vibration was received from the PTO. In all the cases described, forced vibration was used, that is, additional energy was necessary to create it. The total energy consumption for the entire process was greater than the energy consumption for soil treatment without vibration. But there are ways to get vibration without additional energy consumption. In these methods, variable soil resistance and spring fastening of the working bodies to the frame of the plough are used. This vibration is called spontaneous, it occurs in the self-oscillation mode. The aim of the study is to create a plough with vibrating organs in the mode of self-oscillation.

\section{MATERIALS AND METHODS}

The positive effect of vibration on the reduction of the resistance force of the working body is not only due to the violation of cohesion and increase of tension between soil conglomerates as indicated in the source [1]. A significant role is played by reducing the friction coefficient of soil on the working body. We conducted laboratory studies of the effect of vibration on the coefficient of friction of the soil on the steel 
sheet. The sheet was fixed on the stand with an adjustable angle. The box without a bottom was mounted on it. The structural black soil was poured into the box so that it protruded beyond the box. Soil moisture was $14 \%$. Only the soil was in contact with the sheet, and the box did not touch the sheet. A vibrator in the form of an electric motor with a power of $250 \mathrm{~W}$ with an imbalance was attached to the sheet. During motor operation, the sheet vibrates with a frequency of $22-24 \mathrm{~Hz}$ and an amplitude of 2-4 $\mathrm{mm}$. The angle of the sheet slowly increased until the beginning of the movement of the drawer. The average value of the friction angle of the soil on steel was $\varphi=31,4^{\circ}$ with the mean square deviation of $\sigma=0,17^{\circ}$. The vibration reduces the angle of friction to $\varphi=26.5^{\circ}$ with an average square deviation of $\sigma=0.57^{\circ}$. The coefficient of friction takes respectively on the value of $\mathrm{f}=0,61$, without vibration and $\mathrm{f}=$ 0.50 - for vibration of the friction surface. Laboratory experiments have shown that vibration can reduce the coefficient of friction by $18 \%$. Before setting field experiments, theoretical calculations of the effect of the friction angle of soil on the steel resistance force of one working body of the plough were made. By means of geometric constructions of forces acting on the plow body, which consists of a ploughshare and a moldboard, analytical dependences are obtained that allow one to calculate the resistance force of the working body depending on the angle of friction of the soil on the steel and the speed of the plough. The calculation results are presented in the form of a graph in figure 1. There were the following initial data: the length of the soil layer located on the surface of the body -1.27 $\mathrm{m}$; soil density $-1180 \mathrm{~kg} / \mathrm{m} 3$; width of the working body -0.45 $\mathrm{m}$; depth of plowing $-0.24 \mathrm{~m}$; distance of movement of the soil layer $-0.60 \mathrm{~m}$; formation rotation angle $-148^{\circ}$. The angle of shift of the soil varies from 39 to $42^{\circ}$, the specific resistance of the soil to crumpling of $-35.5 \mathrm{kN} / \mathrm{m}^{2}$.

Since vibration reduces the frictional angle from $31.4^{\circ}$ to $26.5^{\circ}$, at a plough speed of $\mathrm{V}=2.0 \mathrm{~m} / \mathrm{s}$, the drag force of each plough body was expected to decrease from 9.3 to $8.4 \mathrm{kN}$, that is, by $9.7 \%$. To test this hypothesis in the field, a plough with six working bodies was made; each of them had a width of 0.45 $\mathrm{m}$. His moldboards were striped. But the main feature of this plow was the rack of the working bodies, with which they were attached to the frame. These racks consisted of four strips, folded in a package and oriented along the movement of the unit (figure 2). The strips were made of spring steel. The longitudinal orientation of the strips is selected so that the working body can vibrate in the transverse direction with respect to the direction of movement of the plough. When plowing, there are pulsating loads in the longitudinal and lateral directions, as in the soil there are structural inhomogeneities, for example, in the form of lumps with the roots of corn or sunflower. These pulsating forces cause the vibration of the instrument. In technology, there is a concept of vibration speed. This is the maximum speed of the tool when this speed changes sinusoidally:

$$
V_{1}=\omega \cdot A=2 \cdot \pi \cdot f \cdot A,
$$

where $V_{l}$ is the vibration velocity of the tool or working element, $\mathrm{m} / \mathrm{s}$;

$\omega$ - circular crank frequency in the drive mechanism, rad./s; $A$ - the amplitude of the oscillations, m;

$f$ - the oscillation frequency, or the number of crank revolutions per second, $\mathrm{Hz}$.

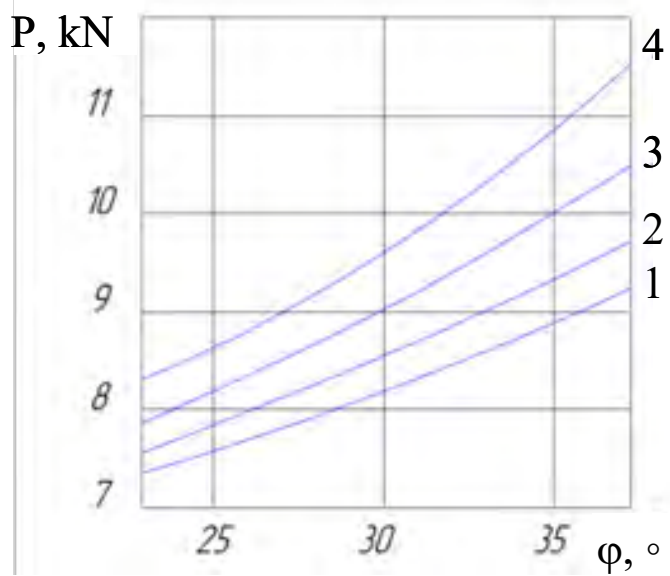

Fig. 1. Graph of dependence of the resistance force of the plough working body on the angle of friction of the soil against steel and the speed of the plough: $1-V=1.0 \mathrm{~m} / \mathrm{sec} ; 2-V=1.5 \mathrm{~m} / \mathrm{sec} ; 3-V=2.0 \mathrm{~m} / \mathrm{sec} ; 4-V=2.5 \mathrm{~m} / \mathrm{sec}$

In case of longitudinal vibrations, it is necessary that the speed of vibration should be greater than the speed of the plough. Only then there is instantaneous separation of the tool from the material to be processed; there will be a shock effect, and vibration will be effective. This is possible only in case of forced vibration with additional power consumption. In case of lateral (or vertical) fluctuations of the working body, the speed of the plough does not matter. Even with spontaneous vibration with its small frequency and amplitude, separation or mutual movement of the material and the tool will be observed. Therefore, to increase the positive effect of using spontaneous vibration, the lateral direction of vibration was chosen. Another feature of the working bodies of the experimental plough was that the moldboards were also made of spring strips. The front ends of the strips are clamped in disc springs. Each band vibrates autonomously [6]. 

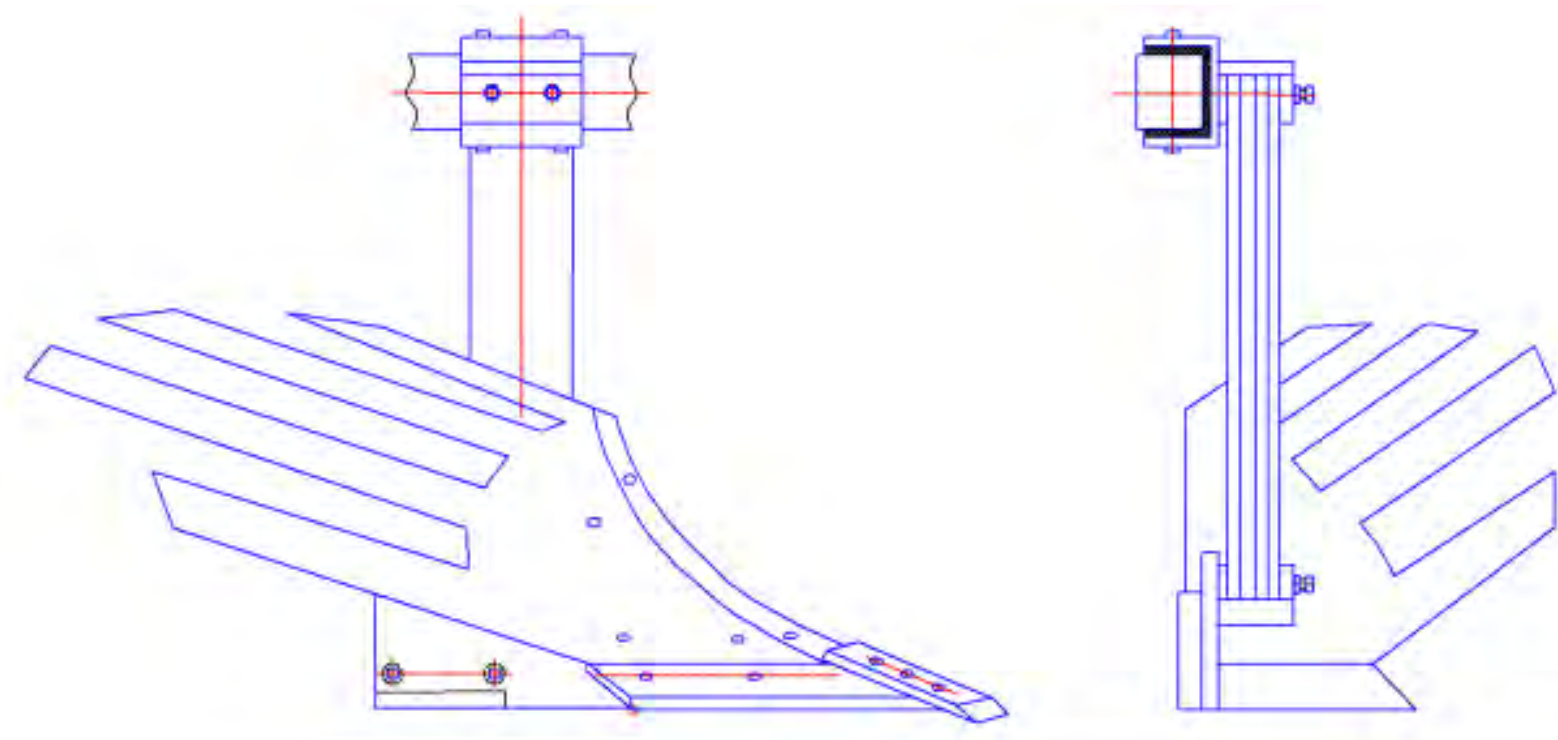

Fig. 2. A scheme of the working body of the experimental plough

\section{MAIN RESULTS OF THE STUDY}

Field tests of the experimental mounted plough with six hulls were carried out in the unit with a tractor K-744 with a capacity of $257 \mathrm{~kW}$. One working body had a width of $45 \mathrm{~cm}$ and the width of the entire plough was $2.7 \mathrm{~m}$. The plough worked on black steam, the soil surface to a depth of $5-7 \mathrm{~cm}$ was treated with disk tools. Soil moisture in layers from zero to $30 \mathrm{~cm}$ varied from 8 to $16 \%$, hardness -from 0.35 to $0.94 \mathrm{MPa}$. The depth of plowing was $30 \mathrm{~cm}$; the speed of movement was $2.15 \mathrm{~m} / \mathrm{sec}$. The vibrations of the rear working body were filmed; the tractor load level was estimated by the wheel slip. The results of the study of the experimental plough were compared with the performance of another plow, which had no vibration of the working bodies. As a result of experiments it was found that the spontaneous vibration of the working bodies had reduced the traction resistance of the plough by $14.5 \%$. The amplitude of the working body vibrations at the level of the ploughshare reached $5 \mathrm{~mm}$; the frequency was $8-10 \mathrm{~Hz}$. A clear sign of the effect of vibration was the relaxation of bolt connections throughout the plough. To eliminate this drawback, rubber pads with a thickness of $1 \mathrm{~mm}$ were installed in the places of fastening of the racks to the frame of the plough. Spontaneous vibration of the working parts of the plow reduced the resistivity of the soil from 6.45 to $5.52 \mathrm{~N} / \mathrm{cm} 2$. Field experiments showed that, in addition to reducing the frictional force, vibration promotes the appearance of advanced microcracks in the soil, prevents the soil from sticking to the working organ and removes the hanging weeds. In the conditions of long-term operation in one of the farms of the Voronezh region, a semi-mounted plow with a $\mathrm{T}-150 \mathrm{~K}$ tractor with a capacity of $120 \mathrm{~kW}$ worked. The plow had four working cases. The width of the plough was $1.8 \mathrm{~m}$; all working bodies had vibrating racks, that is, the plow worked with the use of spontaneous vibration of working bodies. The direction of random oscillations did not coincide with the direction of movement of the unit. Working bodies vibrated in the transverse direction. At a speed of $9.0 \mathrm{~km} / \mathrm{h}$ the unit showed productivity per hour of pure work of $1.62 \mathrm{ha} / \mathrm{h}$. Another one of the same unit, but without the use of vibration, worked side by side on the same field. Its average speed was equal to $7.6 \mathrm{~km} / \mathrm{h}$, and the productivity per hour of pure time was $1.37 \mathrm{ha} / \mathrm{h}$. In this case, the use of spontaneous vibration of the working bodies allowed increasing the productivity of the arable unit by $18 \%$.

As for the forced vibration, it can be implemented most simply without the use of power take-off shaft and transmission mechanisms. If you replace the support wheel of the mounted plow with a metal polygon, then when you move around the field, the plow will bounce, transferring vibrations to the working organs in the vertical direction [7]. In the transport position, the polygon should not touch the road, so the plough should be hinged (figure 3 ). The polygon is wider than the pneumatic wheel and is made of rods to avoid sticking with wet soil (figure 4).

The support faces of the polygon consist of removable rods 1 and permanent rods 2. The geometric calculations of the rational parameters of the polygon show that the constant bars should be on a circle with a diameter of $750 \mathrm{~mm}$. Removable rods are placed in the corners of the polygon with eight faces. Then the vibration amplitude of the entire plough in the vertical direction is $1.15 \mathrm{~cm}$. The extreme positions of the plough at the height of the jumps will vary by $2.3 \mathrm{~cm}$. It contradicts the agricultural requirements for the uniformity of the plowing depth. Vibration frequency at the unit speed of $1.5-2.5 \mathrm{~m} / \mathrm{s}$ will be $5-8 \mathrm{~Hz}$. If you remove the removable bars, there will be no vibration, as the remaining permanent bars are placed on the circumference. 


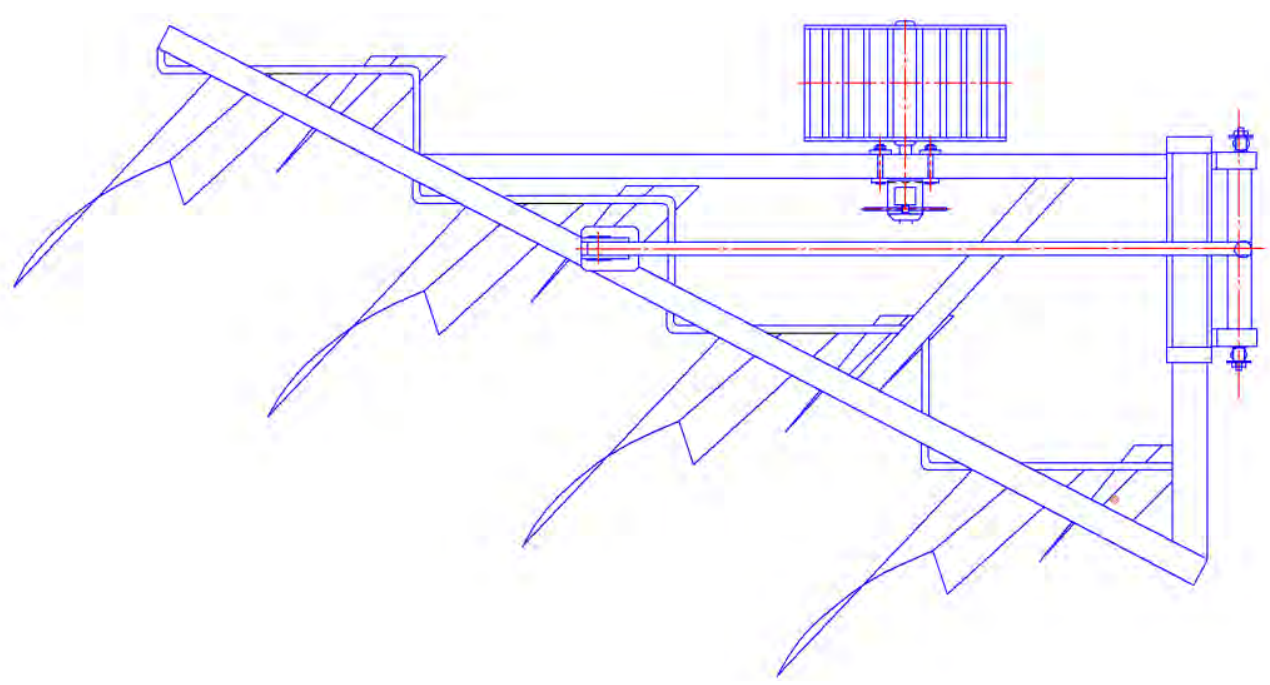

Fig. 3. A diagram of the vibrating plough with a polygon instead of the wheel

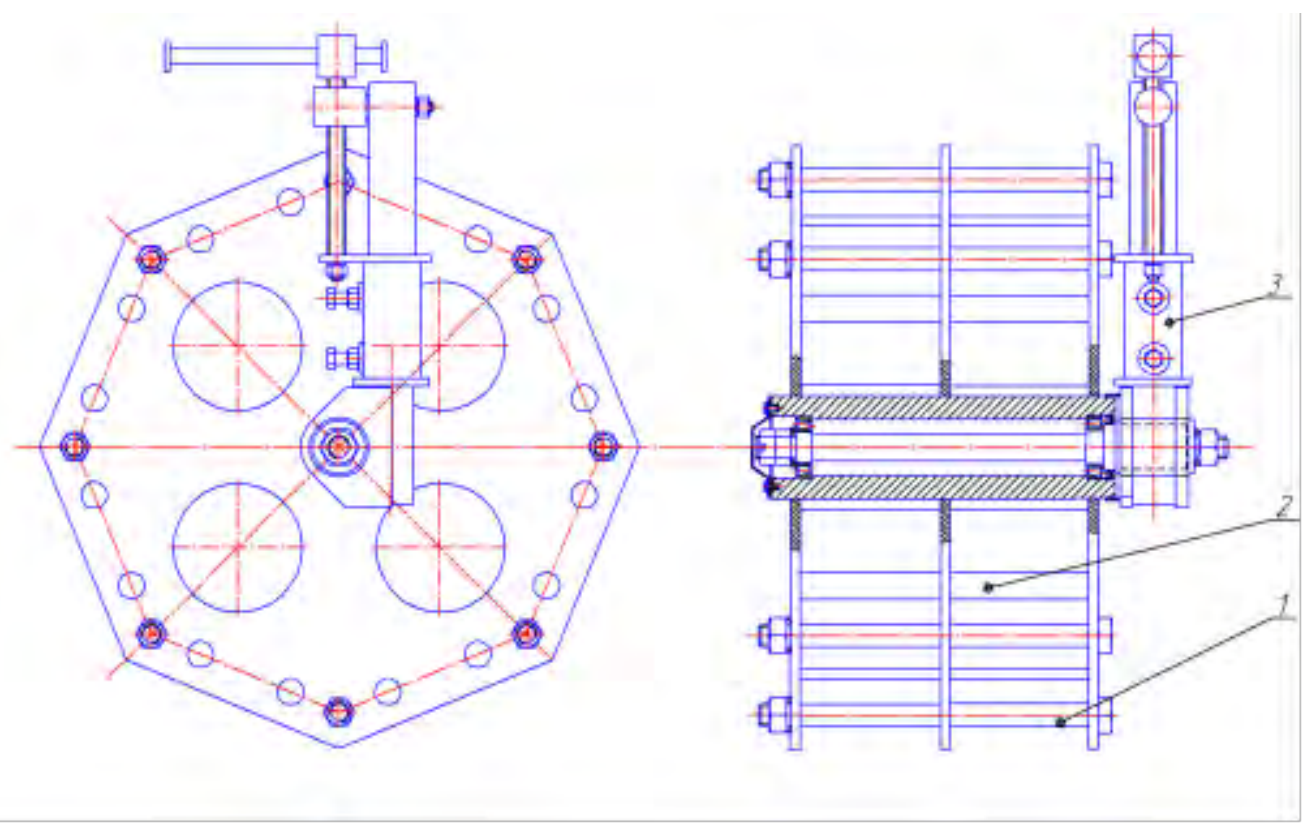

Fig. 4. The supporting polygon of the vibrating plough ( 1 - removable rod; 2 - permanent rod; 3 - mechanism for adjusting the depth of plowing)

\section{CONCLUSION}

Laboratory studies of the soil friction coefficient on the steel vibrating surface showed that at the oscillation frequency of 22$24 \mathrm{~Hz}$ and the amplitude of 2 to $4 \mathrm{~mm}$, the friction coefficient decreases from 0.61 to 0.50 , and the friction angle decreases from 31.4 to $26.5^{\circ}$ compared to friction without vibration. The strength of the traction resistance of the plough depends on the angle of friction of the soil on the working body and the speed of movement of the unit. Analytical calculations have shown that the change in the friction angle within the specified limits and the plough speed of $2.0 \mathrm{~m} / \mathrm{s}$, traction resistance of the working body of the plow, is reduced by $9.7 \%$. Spontaneous vibration of working bodies in the mode of self-oscillation differs from the forced one that does not occur due to additional energy costs, but due to variable soil resistance and does not require a significant complication of the design. To increase the effect at a low vibration speed, the direction of the oscillations should not coincide with the direction of the unit movement. Field tests of plows showed that vibration not only reduces the friction force of the working bodies against the soil, but also forms advanced cracks in the soil, eliminates soil sticking of the working bodies and the accumulation of weeds on the working bodies. As a result, traction resistance decreased by $14.5 \%$, soil resistivity decreased from 6.45 to $5.52 \mathrm{~N} / \mathrm{cm} 2$, and the increase in production reached $18 \%$. The most simple design solution 
for forced vibration of the plough can be implemented by replacing the support wheel with a metal correct polyhedron, which will provide vertical vibrations of the entire plough. The frequency and amplitude of the oscillations depend on the speed of movement, the number of faces and the overall size of the polyhedron.

\section{References}

[1] B. Szabo, F. Barnes, S. Sture et al, "Effectiveness of vibrating bulldozer and plow blades on draft force reduction", Transactions of the ASAE, 1998, vol. 41-2, pp. 283-290.

[2] Xi. Zhang, Ch. Wang, Zh. Chen et al, "Design and experiment of a bionic vibratory subsoiler for banana fields in southern China", International journal of agricultural and biological Engineering, 2016, vol. 9-6, pp. 7583
[3] G. Shahgoli, C. Saunders, J. Desbiolles et al, "An investigation into the performance of vibratory tillage using straight and bent leg tines", Soil management for sustainability, 2006, vol. 38 p. 21.

[4] T. Niyamapa, V. M. Salokhe, "Soil disturbance and force mechanics of vibrating tillage tool", Journal of terramechanics, 2000, vol. 37-3, pp. 151-166.

[5] M. I. Dawelbeit, M. E. Wright Design and testing of a vibratory peanut digger, Applied engineering in agriculture, 1999, vol. 15-5, pp. 389-392.

[6] V. V. Vasilenko, S. V. Vasilenko, D. V. Sturov, G. A. Khalfin, "Banded plow blade", Pat. 2426290 RF IPC A01B 15/08, patent owner: Voronezh SAU, No. 2010112577/21, 2011

[7] V. V. Vasilenko, S. V. Vasilenko, A. A. Muhin, "Mounted vibrating plow", Pat. 2478270 RF IPC A01B 11/00, A01B 3/36, patent owner: Voronezh SAU, No. 2011141674/13, 2013. 